\author{
dr Henryk Hollender \\ Uczelnia Łazarskiego w Warszawie \\ h.hollender@lazarski.edu.pl
}

\title{
PRZYWRÓĆMY BIBLIOTEKOZNAWSTWO PORÓWNAWCZE
}

\author{
LET US BRING BACK COMPARATIVE LIBRARIANSHIP
}

\begin{abstract}
Abstrakt
Porównania bibliotek prowadzone pod szyldem bibliotekoznawstwa porównawczego (czasem także $\mathrm{z}$ dopowiedzeniem: $i$ międzynarodowego) to nurt badawczy i dydaktyczny, który co pewien czas pojawia się w Polsce, aby następnie zniknąć. Równocześnie jednak bibliotekarze polscy przejawiają niewielką aktywność międzynarodową, a głównym narzędziem utrzymywania kontaktu ze światowymi tendencjami jest użytkowanie produktów technicznych, które znane są w innych krajach. Tymczasem porównanie bibliotek powinno pomagać w krytycznej ocenie swoich osiągnięć, w dobieraniu źródeł inspiracji, w przestrzeganiu przed niekorzystnymi decyzjami itd. Autor zwraca uwagę, że w globalnym świecie wszystko może być przedmiotem transferu, a więc także porównywania, choć większość autorów koncentruje się na działalności organizacji międzynarodowych i na wielkich projektach, instytucjonalizujących współpracę bibliotek. Podaje przykłady tematyki godnej badań i analiz oraz autorów, którzy ją podejmują.
\end{abstract}

Słowa kluczowe: bibliotekoznawstwo porównawcze, bibliotekoznawstwo międzynarodowe, bibliotekarstwo polskie, dobre praktyki, modernizacja bibliotek, współpraca bibliotek, Lor Peter Johan, kazusy biblioteczne, bibliotekarstwo poradzieckie.

\footnotetext{
Abstract

Comparisons of libraries conducted under the banner of comparative librarianship (sometimes with the addition of: and international) is a research and didactic trend, which every now and then appears in Poland, to eventually fall into oblivion. At the same time, Polish librarians show little
} 
international activity, and the main tool for maintaining contact with global trends is the use of technical products known in other countries. Meanwhile, this is comparing libraries which should help to critically assess their achievements, select sources of inspiration, abide by unfavourable decisions, and so on. We would like to point out that in the global world, everything can be the subject of transfer and comparison, although the majority of authors focus more on the activities of international organizations and large projects than institutionalize the cooperation of libraries.

Keywords: comparative librarianship, international librarianship, Polish library science, best practice, modernization of libraries, cooperation of libraries, Peter Johan Lor, cases in librarianship, post-Soviet librarianship.

Biblioteki, bez względu na to, czy uczestniczą we współpracy zewnętrznej, realizują projekty, są ogniwami sieci bibliotecznych itp., to utrzymują rozmaite kontakty i czerpią z tego korzyści. Można przyjąć, że zasadniczą spośród nich jest transmisja dobrych praktyk, a czasem także stwarzanie okazji do uogólnień o charakterze poznawczym. Jedno wspiera tu drugie. Bez porównań o charakterze menedżerskim trudno sobie wyobrazić zarówno dokonywanie pożytecznych zapożyczeń, jak i budowanie tożsamości zawodowej. Z porównań wynikają zaś co najmniej nowe wizje, a może także poprawa skuteczności zarządzania i wprowadzanie trwałych, sprawdzonych kryteriów kształtowania jakości.

\section{Komparatystyka - niezbędna metoda, oczywista postawa}

Porównywanie może prowadzić do ujednolicania stosowanych rozwiązań lub też odwrotnie - pogłębiania różnic dla osiągnięcia pierwszeństwa, przewagi czy oryginalności. Jak się jednak zdaje, biblioteki obecnie raczej upodobniają się do siebie niż różnicują. Do wspólnego mianownika doprowadza je stosowanie tych samych norm, powszechna dostępność tych samych produktów lub usług, współpraca w programach takich jak: współkatalogowanie, ochrona zabytków czy likwidacja zagrożeń takich jak kwaśny papier. Globalna dominacja kilku największych platform i serwisów ujednolica obyczajowość pracowników informacji i ich kultury organizacyjne.

Zarówno w prowadzeniu działalności informacyjnej, jak i w publikowaniu mamy do czynienia $\mathrm{z}$ przekraczaniem ograniczeń związanych z lokalnością. Każda instytucja może być dawcą i biorcą rozwiązań 
globalnych - globalizacja wyznacza pole działania, buduje skalę wyzwań, czyni wszystkie instytucje podatnymi na te same wpływy. Za dziewiętnastowieczną migracją mas ludzkich poszło wzmocnienie światowego obiegu idei. Wyrósł nowy „internacjonalizm”, niekoniecznie ideologiczny, przejawiający się raczej jako postawa szukania partnerstw bez ograniczeń. Wszelkie naprawianie, czy zmienianie świata ma dziś zasięg globalny konwencje, organizacje, ruchy pokojowe i ekologiczne, umiędzynarodowienie nauki itp. - podobnie zresztą jak przedsiębiorczość.

Można rozważać, czy z samorzutnego przenikania wzorców wynika tendencja do ciągłego, profesjonalizującego się porównywania, prowadzonego w centrach badań i analiz, think tankach, wyspecjalizowanych jednostkach naukowych, czy też odwrotnie - to porównywanie stymuluje ruch, adaptację, utratę lęków wobec obcości. Jasne, że porównywanie jest we wszystkich sytuacjach społecznych czymś w rodzaju elementarnego, naturalnego odruchu, nie każde jednak prowadzi do komparatystyki rozumianej jako czynność lub dziedzina zaawansowana. Samo naśladownictwo („podpatrywanie”) nie jest porównywaniem w sensie naukowym, ponieważ polega na rozpoznawaniu i przenoszeniu pojedynczych, jednorodnych, łatwo rozpoznawalnych elementów, podobnie jak wszelkie „przeszczepiania” i inne operacje wywodzone z przeświadczenia, że „dawca” stoi o wiele wyżej niż „biorca”.

W praktyce takie zapożyczenia zdarzają się wprawdzie często, ale mają na ogół ograniczoną produktywność. Jako przykłady niech posłużą okoliczności, w jakich powstała Konferencja Dyrektorów Bibliotek Akademickich Szkół Polskich. Była to próba wprowadzenia w Polsce odpowiednika brytyjskiej Standing Conference of National and University Libraries ${ }^{1}$. Podobnie pasywny charakter miało stworzenie w Polsce pewnej liczby „formatów” Dublin Core poprzez kilkakrotne tłumaczenie Dublin Core Metadata

1 Uwaga ta nie ma naturalnie na celu wystawienia jakiejkolwiek całościowej oceny KDBASP, której bogatą historię przedstawia np. następujące opracowanie, zasadnie wprowadzone do programu konferencji odbywającej się w Ukrainie: M. Górski: Konferencja dyrektorów bibliotek Akademickich Szkół Polskich (KDBASP) - dobra praktyka współpracy polskich bibliotek akademickich [dokument elektroniczny]. W: Сyчacнi проблеми діяльності бібліотеки в умовах інформаиійного суспільства: матеріали шостої міжнародної науково-практичної конференцї, 10-11 вересня 2015 р. Red. О. В. Шишка, I. О. Бєлоус, Р. С. Самотий, А. I. Андрухів. Lwów 2015, s. 5-10. Tryb dostępu: http://ena.lp.edu.ua:8080/handle/ntb/29649 [12 października 2012]. Niestety, KDBASP funkcjonuje zupełnie inaczej niż SCONUL (zob. https://www.sconul.ac.uk/) organizacja, o której rozmawialiśmy z Ivorem Kempem, inicjatorem założenia „stałej konferencji” w Polsce - i nigdy nie osiągnęła porównywalnego znaczenia. 
Element Set, bez rozumienia kontekstów, w jakie uwikłany jest ten tekst, i bez wytworzenia kontrolowanych słowników dla większości atrybutów. Wynikł z tego nielichy bałagan ${ }^{2}$.

$\mathrm{Na}$ tej samej zasadzie, umiejętność i wola porównywania wielu współwystępujących czynników mogą stać się źródłem trwałych i dobrze funkcjonujących rozwiązań, wychodzących daleko poza zwykłe naśladownictwo, choć bez wątpienia je przypominających. Gdybyśmy chcieli przeprowadzić studium przypadku „ile ma być bibliotek na uczelni”, to spostrzeglibyśmy, iż jeszcze zanim ustawodawca zażądał, by w Polsce na każdej uczelni był „system, którego podstawą jest biblioteka”, tendencja do ograniczania liczby bibliotek sieci uczelnianej szła z Zachodu na Wschód. Ale nie uszła zbyt daleko. Kiedy Biblioteka Uniwersytecka w Warszawie (BUW) zaczęła planowanie nowego gmachu i bardzo szybko (1992-1999) przeszła do jego budowy, pięćdziesiąt bez mała bibliotek „wydziałowych” (także instytutowych, a nawet zakładowych), to był ostatni temat, za który Uczelnia jako całość miała siłę się zabrać. W tym samym czasie podobnych rozmiarów Uniwersytet Humboldtów ${ }^{3}$ (UH) w Berlinie wcale nie projektował jeszcze gmachu dla swojej biblioteki centralnej, lecz reorganizował strukturę bibliotek filialnych (Zweigbibliotheken), ograniczając ich liczbę, ujednolicając ich tryb funkcjonowania i wyposażenie. Skutek jest taki, że dziś, w pełnej zgodzie ze starą i nową ustawą o szkolnictwie wyższym, Uniwersytet Warszawski stworzył system składający się nadal z ponad 40 bibliotek, przy czym tylko 23 mają ten sam system (i w nim współkataloguje) co otwarta w 1999 r. Biblioteka Uniwersytecka (architekci Marek Budzyński, Zbigniew Badowski), podczas gdy UH ma 12 bibliotek, rozmieszczonych $\mathrm{w}$ poszczególnych zgrupowaniach na terenie miasta, zwieńczonych powstałym dopiero w 2009 r. gmachem Jacob-und-Wilhelm-Grimm-Zentrum (architekt Max Dudler) ${ }^{4}$. Jest oczywiste, że wszystkie te biblioteki

2 Zob. L. Derfert-Wolf: Jak postugiwać się biblioteką cyfrowa? W: Cyfrowy świat dokumentu: wydawnictwa, biblioteki, muzea, archiwa. Red. H. Hollender. Warszawa 2011, s. 202.

3 Spotykana jest również nazwa „Uniwersytet Humboldta w Berlinie”, poprawnie powinno być „Uniwersytet Humboltów”, ponieważ berlińska uczelnia nosi imię dwóch braci Humboldtów Wilhelma i Alexandra, a ich wizerunki widnieją na znaku uniwersytetu. Zob. też: E. Olszewski: Czy rzeczywiście inwazja przyimka „imienia” w nazewnictwie? "Język Polski” 1976, nr 56(2), s. 155-156.

4 W niniejszym artykule autor opowiada o tym głównie na podstawie własnych doświadczeń. Zob. jednak także: A. Stanis: Biblioteka Uniwersytetu Humboldta przed przeprowadzką. „Bibliotekarz” 2008, nr 12, s. 19-20. 
uczestniczą w eksploatacji wspólnego systemu bibliotecznego i wspólnego katalogu uczelni.

\section{Porównawcze i/czy międzynarodowe?}

Porównania mogą być zatem pouczające, jeśli nie ograniczają się do promocji zwykłego naśladownictwa. Od dekad uprawia się bibliotekoznawstwo - czy bibliotekarstwo - porównawcze, także w Polsce; istnieje kilka przekazów, informujących o konferencji z tego zakresu, która odbyła się w 2007 r. w Uniwersytecie Jagiellońskim ${ }^{5}$. Termin ten pojawia się niekiedy w polskim piśmiennictwie, raczej dawniejszym niż nowszym. Z powodów oczywistych ujęcie porównawcze musi występować na kierunkach informacyjnych na wielu wykładanych przedmiotach. Tym bardziej skonstatować trzeba jego stałą obecność w Stanach Zjednoczonych. Być może chwytliwa okazała się idea „rewitalizacji bibliotekoznawstwa porównawczego”, wyrażona tytułem artykułu, który w 2014 r. wyszedł spod pióra Petera Johana Lora, byłego bibliotekarza narodowego Południowej Afryki oraz dyrektora generalnego IFLA (2005-2008) $)^{6}$. Dziś bibliotekoznawstwo porównawcze to w Stanach Zjednoczonych odrębne kursy w 15 uczelniach ${ }^{7}$. Współczesną literaturę $\mathrm{z}$ tego zakresu zwieńcza International and Comparative Librarianship naszego niestrudzonego odnowiciela ${ }^{8}$. W obiegu widzimy jednak obfite, także dawniejsze piśmiennictwo ${ }^{9}$.

P. J. Lor kładzie nacisk na refleksję teoretyczną i metodologiczną, ale interesuje go także wkład bibliotek do współpracy i pokoju między narodami, co zasługuje na najwyższy szacunek. Natomiast przykładowe zasadnicze zagadnienia, poruszane na takich zajęciach, są różne u różnych wykładowców i generalnie - rozmaite. Podajmy kilka przykładów:

5 Zob. np. M. Jaskowska: Przenikanie i rozpowszechnianie idei oraz doświadczeń. „Biuletyn EBIB” 2007, nr 7(78). Tryb dostępu: http://www.ebib.pl/2007/88/a.php?jaskowska [12 października 2018].

6 P. J. Lor: Revitalizing comparative library and information science: theory and metatheory. „Journal of Documentation” Vol. 70, nr 1 (2014), s. 25-51.

7 Zob. informacje zawarte $\mathrm{w}$ serwisie I[ntermational] C[omparative] L[ibrarianship] communitas. Tryb dostępu: https://iclcommunitas.wordpress.com/about/ [12 października 2018].

8 P. J. Lor: International and Comparative Librarianship. A Thematic Approach. München 2017.

9 Np. Global library and information science: a textbook for students and educators [...]. Red. I. Abdullahi. Wyd. 2. Berlin, Boston 2017; S. A Simsova: Primer of Comparative Librarianshi. London 1982. 
- światowa polityka informacyjna i Global Information Access;

- porównanie narodowych stowarzyszeń bibliotekarskich;

- wpływ globalizacji na zarządzanie bibliotekami;

- prawa własności intelektualnej w różnych krajach;

- rola bibliotek narodowych;

- kultury organizacyjne w bibliotekach;

- kulturowa charakterystyka użytkowników bibliotek.

Widzimy zatem, że „międzynarodowość” zrasta się tu z „porównawczością", ponieważ wielu autorów zaczyna od ujęć globalnych, budowanych zazwyczaj nie na pojęciu globalizacji, przeniesionym z nauk ekonomicznych czy politycznych, ale na własnych doświadczeniach $\mathrm{z}$ działalności w międzynarodowych organizacjach bibliotekarskich i pokrewnych. Autorzy i wykładowcy nie definiują natomiast, jakie warsztatowe czy organizacyjne problemy w wybranych bibliotekach i grupach bibliotek oraz w poszczególnych krajach są szczególnie warte porównań, ewentualnych zapożyczeń lub przekształceń w trakcie przeszczepów do innych kultur czy warunków ekonomicznych. Wolą raczej zaczynać „od góry”, wskazując, jakie problemy czy zjawiska występują najczęściej w skali światowej lub łączą biblioteki, stwarzają im okazje do współpracy. Jak się wydaje, marginalizacji ulega tu kwestia, która nam wydawałaby się najciekawsza: w jaki sposób biblioteki ujednolicają swoje techniki i metody działania, hołdując tym samym standardom, procedurom i wzorcom publicznej obecności, lecz odmiennie, być może, je interpretując i naginając do lokalnej obyczajowości, kultury organizacyjnej czy ograniczeń materialnych ${ }^{10}$.

Sam P. J. Lor utrwala ten kierunek. W przywoływanej powyżej książce International and Comparative Librarianship: A Thematic Approach ${ }^{11}$ kładzie nacisk na zagadnienia metodologiczne oraz humanitarne aspekty działalności informacyjnej. Jeden zaś z najnowszych artykułów tego autora to: Democracy, information, and libraries in a time of post-truth

10 Tematem tego typu byłaby tu komputeryzacja bibliotek w krajach do niej nieprzygotowanych. O ile pamiętamy dawne relacje Ewy Chrzan z jej działalności konsultacyjnej (z Simonem Francisem) w Rosji, licencje na „zachodnie oprogramowanie” w latach dziewięćdziesiątych ub. wieku uzyskiwano tam niekiedy bez umowy na „maintenance”; po instalacji oprogramowanie przechodziło pod opiekę miejscowych informatyków.

11 Zob. P. J. Lor: International and Comparative Librarianship..., dz. cyt. Istnieje kilka wersji tej książki, która „dojrzewała” do wydania na poświęconym jej portalu. Niestety, ani jednego egzemplarza nie włączyły do swoich zbiorów biblioteki reprezentowane w NUKAT i KaRo. 
discourse ${ }^{12}$. Jest więc Lor kolejnym wybitnym bibliotekarzem, który w dążeniu do spójnego przedstawienia tego, co łączy biblioteki, marginalizuje pola o charakterze specjalistycznym czy technicznym. Niemniej jednak wnikliwa recenzja doprowadzi prawdopodobnie do przywrócenia ich $\mathrm{w}$ innych opracowaniach, lub nawet do zwrócenia na nie większej uwagi przez samego P. J. Lora w pracy nad nowym wydaniem. W Polsce nie ma egzemplarza książki i autor niniejszego referatu zna ją jedynie z opublikowanych fragmentów. Dzieło jest imponujące - spójrzmy na jego spis treści, stanowiący wartościowy przewodnik po „zdolności porównawczej” świata książnic i usług informacyjnych ${ }^{13}$.

\section{Jesteśmy w Polsce}

Nie zmienia to faktu, że mimo całej obfitości i zróżnicowania tematycznego, zarówno książka P. J. Lora, jak i działalność jego współpracowników, naśladowców i następców skupiać się będzie na politycznych aspektach funkcjonowania bibliotek, i to $\mathrm{w}$ planie globalnym. Takie jest dzisiejsze rozumienia słowa „international”. Wydaje się jednak, że w Polsce ciekawszy byłby plan lokalny czy raczej regionalny, funkcjonujemy bowiem na pograniczu wyrazistych i mocno zróżnicowanych kultur bibliotecznych, których raczej nie chcemy badać.

W dalszej części artykułu przedstawiono kilka opinii, wynikających z doświadczeń autora, a nie z przeglądu piśmiennictwa, ani tym bardziej badań naukowych. Wydaje się na przykład, że zasadnicze nowości docierają do nas w ogóle nie jako idee biblioteczne, lecz jako innowacje techniczne, pojawiające się wraz z komercyjnymi produktami stanowiącymi podstawę funkcjonowania bibliotek i komunikacji naukowej. Ten temat wart jest systematycznego zbadania, bowiem jego istota ma chyba głębsze korzenie. Skoro sama instrukcja użytkownika (dla bibliotekarza), stanowiąca załącznik do rozwiniętego wielomodułowego systemu bibliotecznego, stanowi właściwie opis wszystkich czynności i procedur zachodzących pomiędzy czytelnikiem, obiektem bibliotecznym i pracownikiem biblioteki, to uczenie się wraz z kupowaniem techniki jest zjawiskiem od dawna

12 Zob.: P. J. Lor: Democracy, information, and libraries in a time of post-truth discours. „Library Management” Vol. 39, nr 5 (2018), s. 307-321.

13 W Załączniku zmieszczono spis treści książki, opublikowany przez autora na jego blogu. Tryb dostępu: https://pjlor.files.wordpress.com/2018/12/Book-contents.pdf [12 października 2018]. 
mocno ugruntowanym. Tego nie trzeba - i nie bardzo można - uczyć się na studiach, tego nawet nie ma sensu podpatrywać $\mathrm{w}$ innej bibliotece. Z kolei digitalizacja jako ruch przyszła ze skanerami. I dalej, do współkatalogowania niezbędne były protokoły wymiany danych w Internecie; to one określiły szczegółowo praktykom kolejność czynności.

Ale jeśli coś można mieć bez licencji i inwestycji, naśladownictwo jest chyba słabsze. Tym bardziej że kontakty między bibliotekami i między ośrodkami kształcenia bibliotekarzy, na których ustanowiona jest nasza wiara w sens porównywania, nie zawsze są jednak silne. Jakież kontakty, jaki wpływ i jakie porównania odzwierciedlała taka oto wypowiedź naszego kolegi, który - przedstawiając w 1999 r. w artykule poświęconym rozbudowie Biblioteki Jagiellońskiej (BJ) plan organizacji magazynów bibliotecznych, użył takiej oto charakterystyki: „[...] koncepcja funkcjonalna BJ sytuuje się pomiędzy zelektronizowaną B[iblioteką] Śl[ąską] a otwartą w pełni na czytelnika BUW?"14. Co to znaczy „sytuuje?”! Co to znaczy „pomiędzy?"! Jasne, że tradycyjny zamknięty magazyn biblioteczny, który jak słusznie zauważa sam autor - można przerobić na otwarty dostęp ${ }^{15}$, znajduje się w pewnym sensie "pomiędzy” zrobotyzowanym magazynem Biblioteki Śląskiej, gdzie nie wchodzi nawet bibliotekarz, a Biblioteką Uniwersytecką w Warszawie, gdzie drogi bibliotekarzy i użytkowników krzyżują się niemal bez ograniczeń. Ale dotyczy to samego magazynu, a nie koncepcji, bo takie magazyny nie wymagały koncepcji, by powstawać, i rozbudowa Biblioteki Jagiellońskiej w latach 90. ubiegłego wieku zastała je już na miejscu. Ich początki, to potrzeba wyłączenia przyrastających lawinowo zbiorów drukowanych z możliwej do ogrzania czytelni. Tu nie było niczego w rodzaju inspiracji przez ideę open stacks (praktykowaną

14 K. Zamorski: Rozbudowa Biblioteki Jagiellońskiej. Problemy zmian funkcjonalnych. „Przegląd Biblioteczny” R. 67, z. 1/2 (1999), s. 42. Cała ta wypowiedź brzmi: „Powstała nasycona elektroniką Biblioteka Śląska, na ukończeniu jest ciekawa architektonicznie i funkcjonalnie Biblioteka Uniwersytecka w Warszawie, kończy się rozbudowa sprawnej funkcjonalnie od dawna Książnicy Pomorskiej. Co na tym tle chcemy osiągnąć? Koncepcja funkcjonalna BJ sytuuje się pomiędzy zelektronizowaną BŚl. a otwartą w pełni na czytelnika BUW. Nie jest naszym zadaniem ocena przyjętych tam rozwiązań. Można się bowiem cieszyć, że wreszcie po latach będziemy mieli się czym pochwalić.”

15 Zwraca na to uwagę sam autor stronę wcześniej: „[...] Nadto zgodziłem się z koncepcją R. Loeglera, którą już w latach 70. omawiał z Władysławem Andrzejem Serczykiem, iż nie należy zamykać przed BJ możliwości przejścia kiedyś w przyszłości na system wolnego dostępu do książek. Jeśli którykolwiek z moich następców podejmie taką decyzję, czytelnik będzie miał do dyspozycji przestronne i wygodne magazyny”. Zob. K. Zamorski: Rozbudowa Biblioteki Jagiellońskiej..., dz. cyt., s. 41. 
skądinąd dla wybranych, ale bez tej nazwy, co najmniej od XVII w.), ani tym bardziej przez tyleż zelektronizowany, co zmechanizowany magazyn, postawiony w Katowicach.

Obecnie kontakty między bibliotekami są chyba jeszcze słabsze, mimo licznie organizowanych konferencji. Wiele dyskusji prowadzonych pomiędzy młodymi bibliotekarzami na facebookowych (innych już nie ma) forach dyskusyjnych wskazuje, że podstawowe pojęcia z zakresu racjonalnej współpracy bibliotek, takie np. jak: rozróżnienie pomiędzy katalogami centralnymi powstającymi metodą „zlewania” rekordów a metodą współkatalogowania, po prostu nie są im znane. Wielkie współczesne nurty reformatorskie, takie jak otwarcie się bibliotek naukowych na wyszukiwarki zintegrowane czy bibliotek publicznych na media nietradycyjne, to raczej pochodne oferty rynkowej i tendencji lifestylowych.

Przez pewien czas natomiast mieliśmy do czynienia z realnym wpływem fundacji wspomagających biblioteki finansowo. Fundacja Andrew W. Mellona uważała, że komputeryzacja bibliotek stanowić będzie jeden z filarów demokratyzacji i modernizacji kraju i wspierała nie tylko zakup zaawansowanych systemów bibliotecznych, ale i obejmowanie katalogowaniem online wszystkich rodzajów zbiorów bibliotecznych oraz zakładanie wielkich katalogów centralnych. Była to oferta dla „powracających do Europy" krajów Europy Wschodniej. Europa poradziecka, mająca własną wyrazistą kulturę biblioteczną, nie była objęta tym programem, z wyjątkiem Estonii i Łotwy ${ }^{16}$. Na tamtejsze biblioteki wpływała przez pewien czas fundacja George’a Sorosa „Open Society Institute” i ich akcja Networking Libraries Program ${ }^{17}$; podobnie działo się w Polsce (Fundacja Batorego sfinansowała m.in. pierwszą sieć komputerową w Bibliotece Uniwersyteckiej w Warszawie). Fundacja Bertelsmanna zakładała nowe biblioteki publiczne dla młodzieży w Olsztynie (Planeta 11) i we Wrocławiu (Mediateka), nakłaniając bibliotekarzy do zaakceptowania nowoczesnej architektury, multimedialnych zbiorów i innego rodzaju odświętności niż takiej, jaka była związana $\mathrm{z}$ wizytą $\mathrm{w}$ tradycyjnej, ponurawej i niedofinansowanej bibliotece w kraju socjalistycznym.

Niezależnie od działalności fundacji, Polska cieszyła się co najmniej od lat 80 . XX w. wystarczającą otwartością i swobodą kontaktów, by żywo

16 Zob. Library automation in transitional societies: lessons from Eastern Europe. Red. A. Lass, R. Quandt. New York 2000.

17 Autor był w drugiej połowie lat 90. przez pewien czas recenzentem, oceniającym projekty składane w ramach tego programu. 
dyskutować o doświadczeniach amerykańskich, skandynawskich, brytyjskich i niemieckich; te zainteresowania wzmogły się jeszcze w latach 90. Oddzielone trudną do przekraczania granicą biblioteki Ukrainy, Białorusi czy Rosji są nam mało znane, choć właśnie stamtąd pochodzi najwięcej studentów zagranicznych. Być może nie dostrzegamy nawet, jak bardzo niektórzy z nich są rozczarowani, że książek nie wypożycza się u nas na cały semestr i że biblioteka nie potrafi ani nawet nie zamierza zapewnić każdemu studentowi obowiązującego podręcznika do każdego przedmiotu. Wytłumaczenie takim studentom, skądinąd w większości nieświadomym specyfiki ani rynku wydawniczego, ani systemów nauczania w Polsce, iż byłoby to niemożliwe, stanowi trudne zadanie dla bibliotekarza, który pragnie obsługiwać sumiennie swoją międzynarodową społeczność. Tym bardziej, że przyczyny takiego stanu rzeczy bywają rozmaite - dla niektórych przedmiotów podręczników w ogóle nie ma, dla innych są w wielkim wyborze, a wykładowcy w trosce o pluralizm ujęć z reguły włączają do sylabusów więcej niż jedną pozycję. A przecież to studenci zagraniczni mają rację: wszystko bowiem zmierza do tego, by podstawowe lektury były w Internecie lub przynajmniej w sieci uczelnianej; nie jest to trudne, wiele uczelni już to w dużym stopniu zrealizowało, a program Otwartego Dostępu (Open Access), z wielką nieśmiałością wdrażany przez kolejne rządy, w końcu może do tego doprowadzić.

Trudniej będzie naśladować podniosłość i swoistą ceremonialność poradzieckich bibliotek - a może w ogóle nie powinno się tego robić warto jednak wiedzieć, że ktoś może widzieć w nich wartość. Biblioteki na całym świecie wahają się chyba, czy powinny czytelnika olśnić, poruszyć i poinformować o czymś, czego sam nie doczytałby w użytkowanych tekstach, czy też zaoferować mu coś w rodzaju poufałego partnerstwa. W tym kontekście dla autora niespodzianką była wizyta w nowej bibliotece Uniwersytetu Lipskiego w głównym kampusie. Tak jakby dwie zasadnicze lokalizacje UB-Leipzig podzieliły się rolami: odmieniona Albertina budowała nastrój, zaś Campus-Bibliothek przy ul. Uniwersyteckiej 3 oferowała wnętrze najprostsze z możliwych funkcjonalnie i estetycznie, ale zlokalizowane za niezwykłą rekonstrukcją staromiejskiej pierzei ${ }^{18}$.

18 Dziękuję organizacji bibliotekarzy niemieckich Bibliothek \& Information Deutschland za sfinansowanie pobytu na Bibliothekartag w Lipsku w 2016 r. Zob. też: H. Hollender, E. Kotyńska: [Sto trzeci] 103. Kongres Bibliotekarzy Niemieckich - Brema, 2014. „Biuletyn EBIB” 2014, nr 6(151). Tryb dostępu: http://open.ebib.pl/ojs/index.php/ebib/ article/view/267/438 [1 października 2015]. 
Wydaje się, że bibliotekom w Polsce brakuje wręcz perspektywy porównawczej i inspiracji płynącej z tego, że ktoś robi coś inaczej. Jak słyszymy, powoli rodzą się w Polsce wdrożenia Patron Driven Acquisitions, ale to jest technika i ta technika znajduje się w ofercie dostawców „kontentu”. Nie zrobiły jednak wcześniej szerszego wrażenia różne metody planowego gromadzenia, takie jak instytucjonalizacja profesorskiej inicjatywy zakupowej (wraz z przydziałem środków), praktykowana w Niemczech, czy powierzenie księgarniom tworzenie ofert według przyjętego wcześniej szczegółowego planu gromadzenia - co przenosi skupienie bibliotekarza z doboru książek „na tytuły” na umiejętność uporządkowania posiadanego piśmiennictwa i określenia potrzeb w poszczególnych kategoriach dziedzinowych czy tematycznych.

\section{Podsumowanie}

Wydaje się, że biblioteki dzisiaj są dzięki użytkowanym systemom $\mathrm{w}$ pełni transparentne dla badacza - stosowane przez nie rozwiązania organizacyjne i techniczne można poddawać precyzyjnemu oglądowi, i to zdalnie. Zastosowanie wyszukiwarek zintegrowanych i relacje między katalogami bibliotecznymi a zawartością bibliotek cyfrowych, repozytoriów i baz danych, stopień wdrożenia innowacji w zakresie schematów i formatów danych oraz linkowania danych, zasady dokumentacji i obiegu materiałów stanowiących dziedzictwo kultury, otwieranie bibliotek publicznych na działania społeczne, niepowiązane bezpośrednio z posiadanymi zbiorami, to pola, na których występują zasadnicze różnice między regionami i krajami. Metody porównawcze byłyby także niezbędne w refleksji nad przebiegiem i skutkami modernizacji bibliotek i przemianami w zakresie etyki i pragmatyki służbowej zawodu bibliotekarza. We wszystkich tych obszarach działo się w Polsce dużo. Warto zapytać o oryginalność rozwiązań, źródła postaw promodernizacyjnych, stopień regionalnej czy międzynarodowej atrakcyjności praktyk. Nie pomijajmy porównywania regionów w Polsce i regionów europejskich, nie bójmy się zagadnień warsztatowych, które mogą uchodzić za hermetyczne lub niszowe. 


\section{Załącznik}

Spis treści książki - P. J. Lor: International and Comparative Librarianship: Concepts and Methods for Global Studies

\section{PART I: CONCEPTS}

Chapter 1. From local to global: the expanding horizons of libraries and related information organizations. 1.1. Introduction. 1.2. Periodization of library development. 1.3. Libraries - from local to global horizons. 1.4. Horizon 1: Local. 1.5. Horizon 2: Imperial. 1.6. Horizon 3: Universal. 1.7. Horizon 4: National. 1.8. Horizon 5: International. 1.9. Horizon 6: Global. 1.10. Conclusion.

Chapter 2. A field of study and research. 2.1. Introduction. 2.2. Emergence of a professional literature. 2.3. Themes, genres, motives, and values. 2.4. The literature of international librarianship. 2.5. The literature of comparative librarianship. 2.6. Definition and scope of international librarianship. 2.7. Definition and scope of comparative librarianship. 2.8. Distinction between international and comparative librarianship. 2.9. The nation state, methodological nationalism and globalisation. 2.10. Towards global library and information studies. 2.11. Conclusion.

Chapter 3. Conceptual exploration. 3.1. Introduction. 3.2. The need for theory. 3.3. The library concept. 3.4. A universal concept? 3.5. The conduit metaphor: transmission as a conceptual framework. 3.6. Systems frameworks. 3.7. Ecosystems and the LIS environment. 3.8. Culture. 3.9. Libraries and culture. 3.10. Conclusion.

\section{PART II: METHOD}

Chapter 4. Preparing for research: metatheoretical considerations. 4.1. Introduction. 4.2. Method, methodology and metatheory. 4.3. Metatheory, methodology and methods: the Iceberg Model. 4.4. Metatheoretical dimensions. 4.5. Major research paradigms. 4.6. The sociological dimension. 4.7. The teleological dimension. 4.8. The ontological dimension. 4.9. The epistemological dimension. 4.10. The ethical dimension. 4.11. Evaluation of metatheoretical assumptions. 4.12. Towards methodology.

Chapter 5. Methodological decisions. 5.1. Introduction. 5.2. Methodological decisions and metatheory. 5.3. Quantitative and qualitative methodologies. 5.4. Mixed methods. 5.5. The comparative method. 5.6. Theory and mechanics of comparison. 5.7. Terminology. 5.8. Comparative strategy. 5.9. Comparative research designs. 5.10. Selection of countries. 5.11. Typologies and country groupings. 5.12. Selecting an appropriate level 
of analysis. 5.13. The time dimension. 5.14. Evaluation of methodology. 5.15. Conclusion.

Chapter 6. Method: procedures, techniques, instruments. 6.1. Introduction. 6.2. Data sources. 6.3. Concepts. 6.4. Defining concepts. 6.5. Concepts and defining attributes: the qualitative approach. 6.6. Variables and indicators: the quantitative approach. 6.7. Concepts across boundaries. 6.8. Framing questions across cultures. 6.9. Survey design and execution. 6.10. Documentary sources. 6.11. Documents as primary sources. 6.12. Content analysis. 6.13. Bibliometric and related techniques. 6.14. Secondary sources. 6.15. General country information. 6.16. International comparative data - general. 6.17. International comparative data LIS. 6.18. Information on LIS in specific countries. 6.19. Information on international organizations. 6.20. Challenges in using secondary sources. 6.21. Researching in other countries. 6.22. Evaluation of methods. 6.23. Conclusion.

\section{PART III: POLITICAL ECONOMY}

Chapter 7. The political economy of LIS. 7.1. Introduction. 7.2. Political economy. 7.3. International political economy. 7.4. Civil society. 7.5. The business sector. 7.6. The public sector. 7.7. Intergovernmental organizations. 7.8. The digital divide. 7.9. Information/knowledge as an economic good. 7.10. Information as a resource. 7.11. Intellectual property. 7.12. Intellectual property in international context. 7.13. Contesting intellectual property. 7.14. Conclusion.

Chapter 8. Access to knowledge and global flows of information. 8.1. Introduction. 8.2. The access to knowledge movement. 8.3. Mitigating intellectual property restrictions. 8.4. Pushback: international advocacy for access. 8.5. Open access. 8.6. Other legal strategies. 8.7. Radical and extra-legal resistance. 8.8. Globalization and information flows. 8.9. Global information flows: North-South. 8.10. Global information flows: SouthNorth. 8.11. Global information flows: South-South. 8.12. Global information flows: North-North. 8.13. Conclusion.

\section{PART IV: INFLUENCE}

Chapter 9. International influence and diffusion of ideas in LIS. 9.1. Introduction. 9.2. Influence. 9.3. Diffusion. 9.4. Diffusion of innovations: the Rogers model. 9.5. Limitations of the Rogers model. 9.6. Other research traditions. 9.7. Diffusion in LIS. 9.8. Diffusion in ICT and information systems. 9.9. Diffusion of policy. 9.10. Policy transfer in applied 
social science disciplines. 9.11. Policy transfer in education. 9.12. Towards a framework for studying transfer in LIS. 9.13. Exhibit A: Le retard français. 9.14. Conclusion.

Chapter 10. Colonialism, development, and aid. 10.1. Introduction. 10.2. Colonization and colonialism. 10.3. Political-economic consequences of colonialism. 10.4. Decolonization. 10.5. After colonialism. 10.6. Developing countries. 10.7. Poverty. 10.8. Development. 10.9. Theories of development. 10.10. Development aid. 10.11. Donors. 10.12. Donor motives. 10.13. Forms of aid. 10.14. Process. 10.15. Recipients. 10.16. Context. 10.17. Outcomes. 10.18. Conclusion.

Chapter 11. LIS development and aid (1). 11.1. Introduction. 11.2. LIS development questions. 11.3. Factors influencing LIS development. 11.4. LIS development trajectories. 11.5. Historically literate realms. 11.6. Exhibit B: China. 11.7. Latin America. 11.8. Former colonies of large-scale European settlement. 11.9. Exhibit C: The Carnegie Corporation, Canada, and New Zealand. 11.10. Conclusion.

Chapter 12. LIS development and aid (2). 12.1. Introduction. 12.2. Former colonies of limited European settlement. 12.3. Exhibit D: Francophone Africa. 12.4. The former Russian Empire and Soviet sphere of control. 12.5. Exhibit E: The European Union and Central and Eastern Europe. 12.6. Five dimensions of LIS development and aid. 12.7. Systemic aid. 12.8. Conclusion.

Conclusion 1. What have we learned? 2. Reflections on the generalized development trajectories. 3. Reflections on the use of theory. 4. Has international and comparative librarianship failed? 5. Is there a future for international and comparative librarianship?

Bibliography, Index.

\section{Bibliografia}

1. Comparative and international librarianship. Red. S. Kawatra. New York 1987.

2. Derfert-Wolf L.: Jak postugiwać się biblioteka cyfrowa? W: Cyfrowy świat dokumentu: wydawnictwa, biblioteki, muzea, archiwa. Red. H. Hollender. Warszawa 2011, s. 201-237.

3. Global library and information science: a textbook for students and educators. Red. I. Abdullahi. Wyd. 2. Berlin, Boston 2017.

4. Górski M.: Konferencja dyrektorów bibliotek Akademickich Szkót Polskich (KDBASP) - dobra praktyka wspótpracy polskich bibliotek akademickich. W: Сучасні проблеми діяльності бібліотеки в умовах інформаційного суспільства: матеріали шостої міжнародної науково- 
-практичної конферениї, 10-11 вересня 2015 р. Red. O. В. Шишка, I. О. Бєлоус, Р. С. Самотий, А. I. Андрухів. Lwów 2015, s. 5-10. Tryb dostępu: http://ena.lp.edu.ua:8080/handle/ntb/29649 [12 października 2012].

5. Hollender H., Kotyńska E.: [Sto trzeci] 103. Kongres Bibliotekarzy Niemieckich - Brema, 2014. „Biuletyn EBIB” 2014, nr 6(151). Tryb dostępu: http:// open.ebib.pl/ojs/index.php/ebib/article/view/267/438 [1 października 2015].

6. Jaskowska M.: Przenikanie i rozpowszechnianie idei oraz doświadczeń. „Biuletyn EBIB” 2007, nr 7(78). Tryb dostępu: http://www.ebib.pl/2007/88/a.php?jaskowska [12 października 2018].

7. Libraries in the early 21st century, an international perspective. T. 1-2. Red. R. N. Sharma. Berlin 2017.

8. Libraries in the political process. Red. C. Stilwell, P. J. Lor, R. Bats. Baltimore 2016.

9. Library automation in transitional societies: lessons from Eastern Europe. Red. A. Lass, R. Quandt. New York 2000.

10. Lor P. J.: Democracy, information, and libraries in a time of post-truth discours. „Library Management” Vol. 39, nr 5 (2018), s. 307-321.

11. Lor P. J.: International and Comparative Librarianship: A Thematic Approach. München 2017.

12. Lor P. J.: Revitalizing comparative library and information science: theory and metatheory. „Journal of Documentation” Vol. 70, nr 1 (2014), s. 25-51.

13. McCook K., Ford B. J., Lippincott K.: Libraries: Global reach, local touch. Chicago 1998.

14. Simsova S.: A Primer of Comparative Librarianship. London 1982.

15. Stanis A.: Biblioteka Uniwersytetu Humboldta przed przeprowadzka.. „Bibliotekarz" 2008, nr 12, s. 19-20.

16. Stueart R. D.: International librarianship: a basic guide to global knowledge acess. Lanham 2007.

17. Zamorski K.: Rozbudowa Biblioteki Jagiellońskiej. Problemy zmian funkcjonalnych.„Przegląd Biblioteczny” R. 67, z. 1/2 (1999), s. 31-43. 